IOS Press

\title{
On the overwintering ability of Drosophila suzukii in South Tyrol
}

\author{
Florian N. Zerulla ${ }^{\mathrm{a}, \mathrm{b}, *}$, Silvia Schmidt ${ }^{\mathrm{a}}$, Martin Streitberger ${ }^{\mathrm{a}}$, Claus P. W. Zebitz ${ }^{\mathrm{b}}$ and Roland Zelger ${ }^{\mathrm{a}}$ \\ ${ }^{a}$ Laimburg Research Centre for Agriculture and Forestry, Laimburg, Vadena, Ora, Italy \\ ${ }^{\mathrm{b}}$ University of Hohenheim, Institute of Phytomedicine, Department Applied Entomology, Stuttgart, Germany
}

\begin{abstract}
.
BACKGROUND: Drosophila suzukii became one of the most dangerous pests in fruit crops and vineyards in Europe since 2009. Lacking knowledge of the overwintering biology under European environmental conditions makes an environmentally friendly control of this invasive pest difficult.

OBJECTIVE: The objective of this study was to investigate its hibernation capability under the climatic conditions of South Tyrol, Italy.

METHODS: Monitoring flight activity by baited traps revealed an overwintering location in the Adige valley. We determined the reproductive status of females trapped weekly at "Schlossleiten" from August 2012 until September 2013 by dissecting their abdomens. For further potential correlation between overwintering locations, reproductive status, and climatic conditions were assessed.

RESULTS: The microclimatic conditions of single locations affected overwintering success and suggest the aggregation of adults in most favourable hibernation sites where a high proportion of females is able to survive. However, in spring some of the females showed degenerated reproductive organs. Dissection of abdomens evinced a reproductive diapause, which appears to be affected by winter climatic conditions, the nutritional status, and food availability.

CONCLUSIONS: $D$. suzukii is able to overwinter in the South Tyrolean area. Control and management of the potential hibernation
\end{abstract} sites may delay the population dynamics in the following season.

Keywords: Drosophila suzukii, overwintering, reproductive status, microclimatic data, flight activity

\section{Introduction}

The invasive pest Drosophila suzukii Matsumura (Diptera: Drosophilidae) became an important economic pest of soft and stone fruits and grapes in North and South America, Asia, and Europe [1,2]. In contrast to other Drosophila species depositing eggs on damaged fruits, D. suzukii is able to oviposit into healthy immature and ripening fruits $[3,4]$. Developing larvae consume the fruit flesh, and thus degrading fruit quality and making them unmarketable for fresh consumption or industrial processing. Because of the high reproductive potential of this species as well as the wide host range, it is very difficult to control the pest during the growing season.

The population density and dynamics is strongly dependent on hibernation survival and winter temperatures, whereas preimaginal development is determined by the prevailing temperature during the vegetation period [5], and the availability of essential food resources. Latest studies show that $D$. suzukii can also successfully reproduce when they are fed with pollen as alternative food only but need fruits for oviposition and larval development [6]. Early flowering plants like Sambucus nigra L. or Cornus mas L. and early fruiting species like Lonicera caerulea L. and Fragaria vesca L. may play an important role to start a new generation in spring. At the beginning of the growing

*Corresponding author: F.N. Zerulla, Laimburg Research Centre for Agriculture and Forestry, Laimburg 6, Vadena 39040 Ora, Italy. Tel.: +49 711459 22393; Fax: +49 711459 22408; E-mail: Florian.Zerulla@uni-hohenheim.de. 


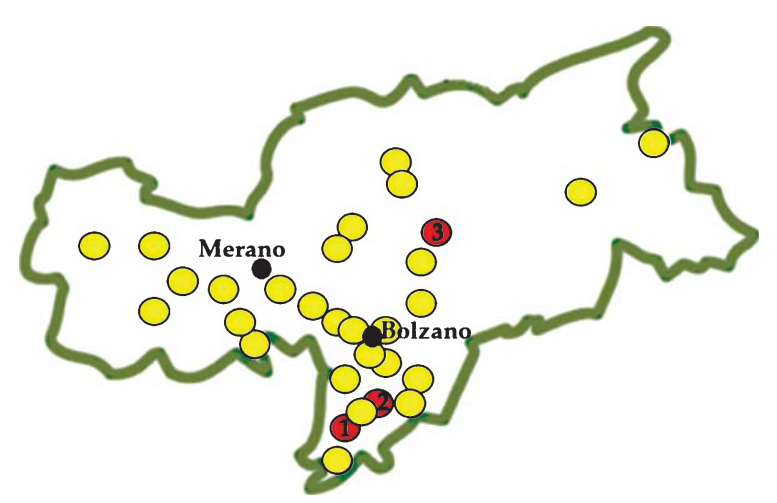

Fig. 1. Distribution of the 30 traps across South Tyrol; Nr. 1: Kurtatsch, Nr. 2: Schlossleiten, Nr. 3: Barbian.

season of cultivated plants, these factors lead most likely to an increasing population and pest pressure, especially after oviposition into fruits of early maturing varieties of strawberries or raspberries $[7,8]$.

According to previous findings and observations, the hibernation is a bottleneck for the survival of populations [6]. For this reason, knowledge of the factors warrant successful overwintering of D. suzukii is of great importance for later estimates of infestation pressure.

First recordings of Drosophila suzukii in South Tyrol have been reported in August 2010. Since 2011, a monitoring program was implemented to observe the flight activity of this species in the South Tyrolean area. 30 locations with more than 60 traps were distributed across South Tirol (Fig. 1). Monitoring of D. suzukii activity detected an overwintering locality in the Adige valley at $300 \mathrm{~m}$ a.s.l. (Schlossleiten, South Tyrol). Three locations (including the overwintering location Schlossleiten), with a high D. suzukii population density during 2013 (red dots in Fig. 1), were chosen for climatic data recordings in the winter season 2013-2014 in order to correlate the population density of overwintering D. suzukii adults with climatic conditions and to observe the flight activity at different altitudes, geographical areas and habitats, and to get knowledge of D. suzukii's phenology in South Tyrol.

Furthermore the physiological status of ovarioles of all females trapped weekly at the hibernation site Schlossleiten was assessed to determine reproductive readiness of the overwintering population.

\section{Materials and methods}

\subsection{Monitoring of flying activity}

Traps (11 plastic bottles "Kartell”, coloured with a ca. $7 \mathrm{~cm}$ wide red band and punctured with holes of 2-3 mm diameter), filled with $200 \mathrm{ml}$ of the attractant Droski-Drink (Sant'Orsola Società Cooperativa Agricola, TN) were controlled weekly from September 2013 until April 2014 at all locations given below. At the same time, the bait was replaced to prevent loss of attractivity. Trapped insects were collected by filtering the liquid and removing debris. The attractant had no adverse effect on trapped specimens when drowned in the fluid for one week.

Drosophila suzukii individuals captured in the attractant were determined, preserved in $70 \%$ ethanol and stored at $6{ }^{\circ} \mathrm{C}$ in a refrigerator for further investigations of the reproductive status of female $D$. suzukii within 14 weeks. Later checks of females collected in the years 2012 and early 2013 revealed that even a longer storage in ethanol did not affect the egg and ovariole status and morphology.

\subsection{Locations (Fig. 1)}

- Kurtatsch (Nr. 1): $200 \mathrm{~m}$ a.s.l., 2 ha blackberry and blueberry plantations in the Adige valley, surrounded by apple orchards with the nearest forest habitat at about $600 \mathrm{~m}$ air flight distance, 
- Schlossleiten (Nr. 2): $300 \mathrm{~m}$ a.s.1., in the Adige Valley, 1,5 ha vineyard on the eastern slope of the mountains, adjacent to natural forests with wild host plants such as blackberries and strawberries,

- Barbian: 900 (Nr. 3) m a.s.l., 3,000 $\mathrm{m}^{2}$ strawberry, blueberry and raspberry plantations in the Isarco Valley on the eastern slope of the mountains, partially adjacent to natural forest habitats.

Traps were collocated on the host plants and in the neighbouring forests.

\subsection{Assessment of the reproductive status of the females}

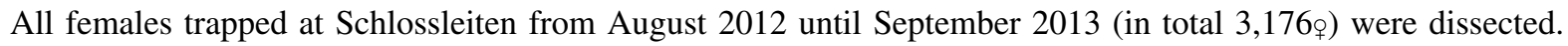
Female reproductive condition was categorized following King et al. [9] (Fig. 2):

1. indiscernible ovarioles

2. unripe ovarioles

3. maturing eggs in ovarioles visible

4. mature eggs with filaments

5. old eggs

\subsection{Microclimatic data recordings}

On Sep. 24th 2013, in the forest at Schlossleiten and Barbian, and on a blackberry bush at Kurtatsch, dataloggers (Easylog-USB-2, Lascar Eletronics) recording hourly temperature $\left({ }^{\circ} \mathrm{C}\right)$ and relative humidity $(\% \mathrm{RH})$ were deployed at $50-100 \mathrm{~cm}$ above ground near to the traps and protected from rain by a small roof.

Waterproof thermosensors were also placed under the forest mulch (Schlossleiten and Barbian), or under the blackberry foliage on the ground (Kurtatsch) in December 2013.

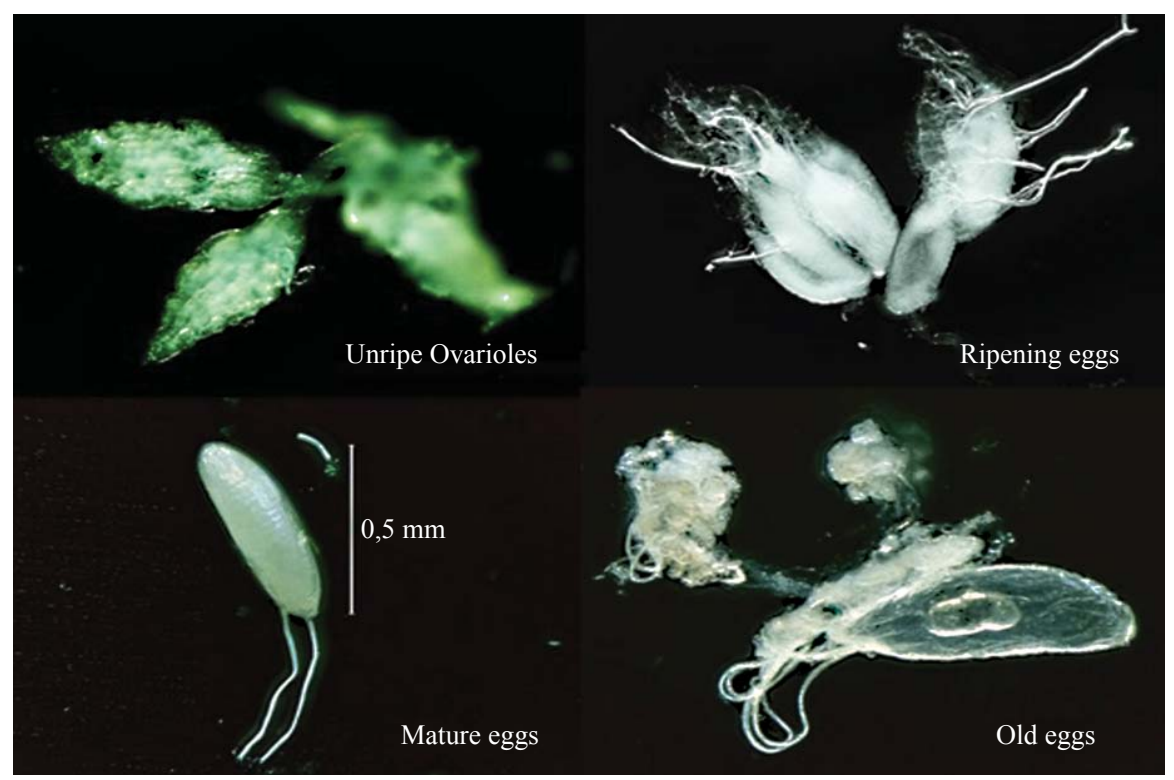

Fig. 2. Categories of reproductive status of $D$. suzukii females. 


\section{Results and discussion}

\subsection{Flight activity and climatic data}

Schlossleiten was the only monitoring site (of 30 sites all over the province area; compare Fig. 1) where constant flight activity was recorded also in the winter period from January to March, in both years 2013 and 2014. In 2013 at Kurtatsch, the flight almost ceased in December and sporadic catches were recorded only in January 2014; in Barbian flight stopped at the end of November 2013 (Fig. 3).

Kurtatsch showed a longer continuous period with weekly mean minimum air temperatures below $0{ }^{\circ} \mathrm{C}(48 \mathrm{th}-4$ th week, except week 52). This was also the only site where, under the mulch foliage, hourly (h) temperatures below $0{ }^{\circ} \mathrm{C}$ were recorded (Fig. 4). In this location, no other refuge for hibernation was available than the ground covered with leaf litter. Other potential natural refuges or human habitats were available at a distance greater than $600 \mathrm{~m}$. Although the mean daily air temperatures $\left(>7^{\circ} \mathrm{C}\right.$, registered starting from week 8) allow flight activity, no D. suzukii were trapped. Presumably the majority of flies could not survive winter in this site.

Schlossleiten also had a period with weekly mean minimum air temperatures below $0{ }^{\circ} \mathrm{C}$ (week 48 in 2013 till week 3 in 2014, except week 52), however, temperatures did not drop below $2{ }^{\circ} \mathrm{C}$ beneath the forest mulch. In contrast

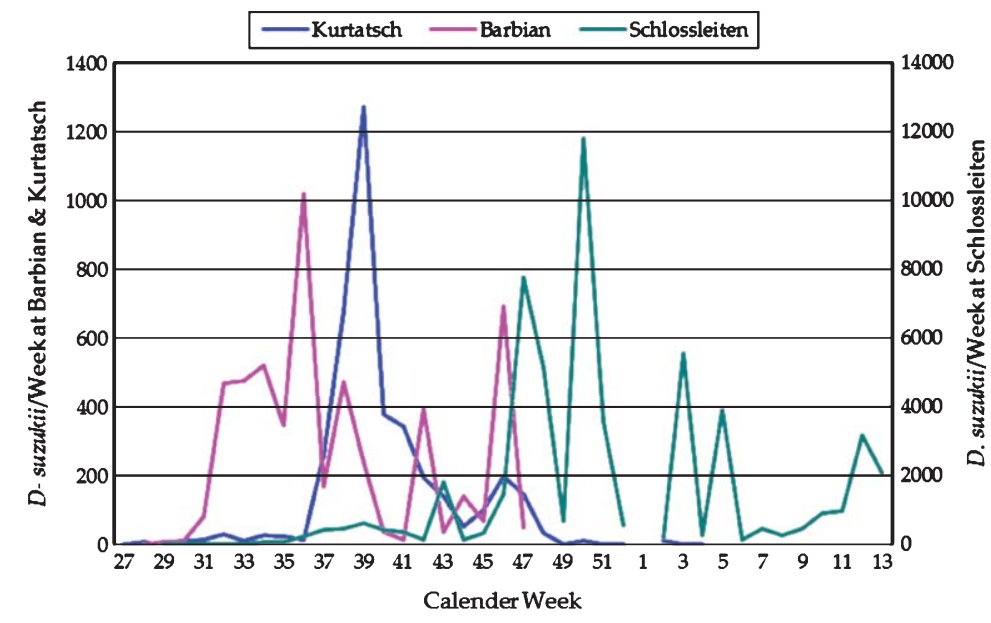

Fig. 3. Flight activity at the locations Kurtatsch, Schlossleiten and Barbian.

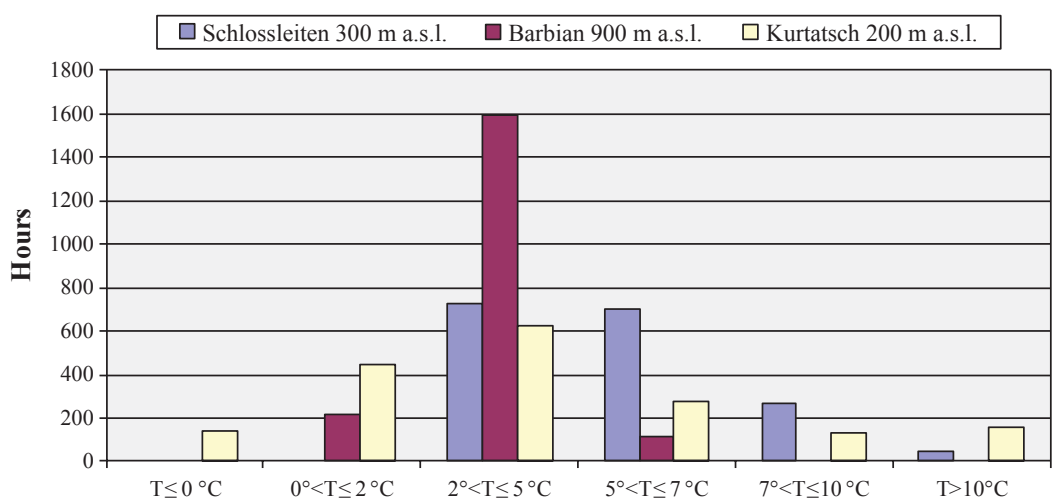

Fig. 4. Hourly $\Sigma$ degree recorded under the mulch in potential refuges during the period Dec. 23rd 2013 until March 13 th 2014 in Schlossleiten, Barbian and Kurtatsch. 
to the other monitored localities, the number of catches in Schlossleiten indicates the presence of a strong population until the end of November in week 50 with up to 8,000 individuals/week, even after the first frost period. In March 2014 up to 3,000 individuals/week were trapped. Thus, it is likely that the majority of the population survived and that the flies choose appropriate sites as overwintering localities.

In Barbian, the oscillations between minimum and maximum daily temperatures were marginal (averaged $5.1^{\circ} \mathrm{C}$ ), and the mean weekly air temperatures ranged for a long period (week 48 until week 9) between $-2^{\circ} \mathrm{C}$ and $+2{ }^{\circ} \mathrm{C}$, with discontinuous course below and above $0{ }^{\circ} \mathrm{C}$. Underneath the forest mulch the hourly temperatures did not drop below $0{ }^{\circ} \mathrm{C}$ and ranged mainly between $2{ }^{\circ} \mathrm{C}$ and $5{ }^{\circ} \mathrm{C}$. Until week 11 , the daily mean air temperatures were still below $7{ }^{\circ} \mathrm{C}$ and, thus, the lacking catches till March could be due to no or a restricted flight activity. However, reliable data on temperature dependent flight activity are lacking. Nevertheless, laboratory results showed that adult longevity decreases progressively at constant temperatures below $10{ }^{\circ} \mathrm{C}$ [5]. So it seems to be more likely that even if the temperatures in refuges were mainly above $2{ }^{\circ} \mathrm{C}$, the very long exposure period $(1,600 \mathrm{~h})$ to temperatures $\leq 5$ ${ }^{\circ} \mathrm{C}$, and with possible exposures to air temperatures of $\geq 10^{\circ} \mathrm{C}$ for very short periods at daytime, caused an increased mortality of the local population.

Generally, both, weekly mean air temperature and weekly minimum air temperature in the respective period (January-March 2014) had $2{ }^{\circ} \mathrm{C}$ higher average temperatures than in year 2013 in the same geographical area. These observations indicate a reproductive diapause in that population, which appears to be influenced by the winter climatic conditions and the availability of nutrients for hibernating adults.

\subsection{Reproductive status of overwintering females}

Considering the entire course of the reproductive status of the females caught at Schlossleiten from August 2012 to April 2014, the number of D. suzukii oscillates stronger than at the other collection sites (Fig. 5), and it may be assumed that generations do no overlap. In contrast, from mid-April till mid-July 2013 no individuals were detected in the traps, which may have several reasons. On one hand, trap attractiveness may have been lower compared to plants being more attractive by matching better the key-stimuli to adults depending on the reproductive status of females similar to the Codling moth, Cydia pomonella. The response of $C$. pomonella mated females with developing oocytes or eggs, was superior to odours of ripe host-fruits compared to unmated females and females with no fat or developing eggs in their abdomen [12]. On the other hand, if the number of catches represent the population density, population density may be low or the population is almost extinct in this period.

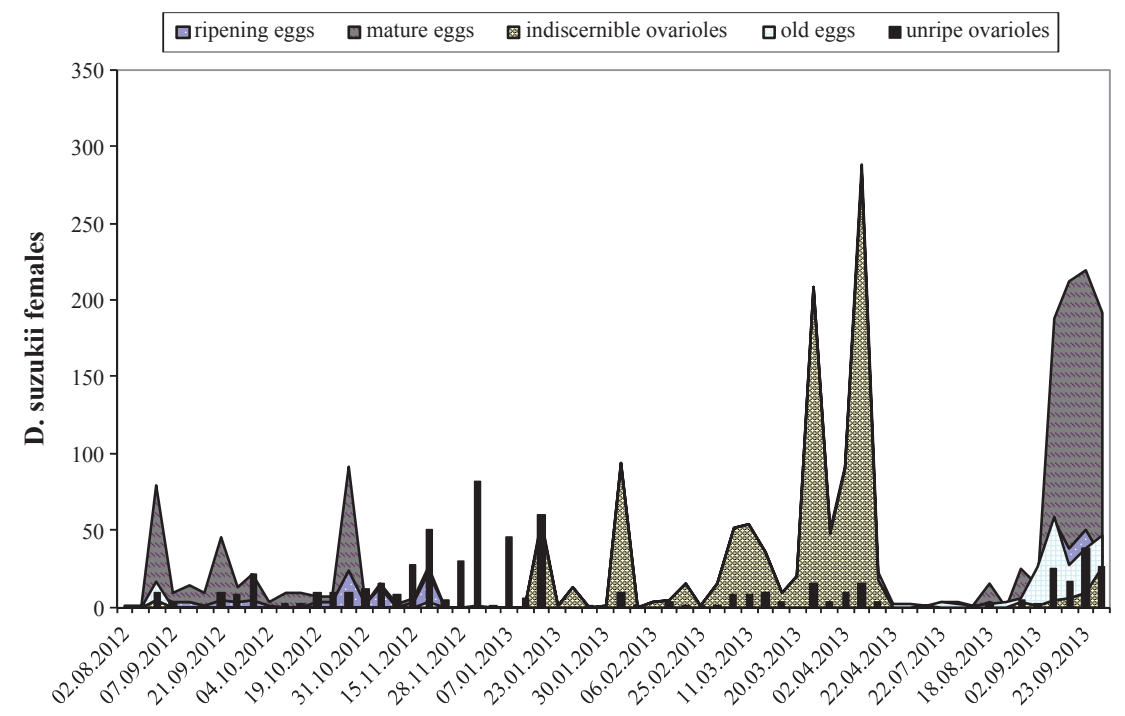

Fig. 5. Reproductive status of females trapped in Schlossleiten during the period August 2012-September 2013. 


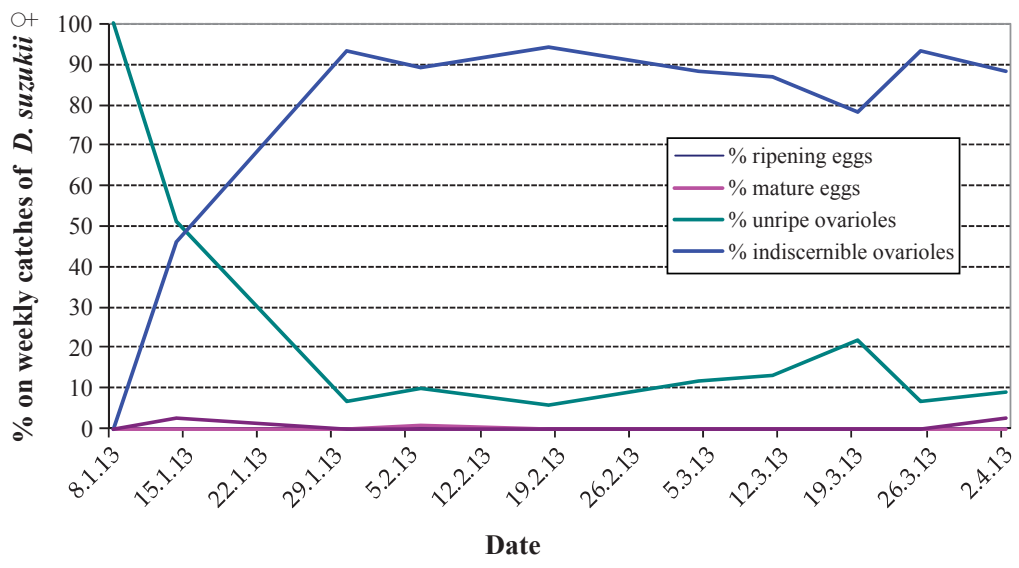

Fig. 6. Percentage distribution of reproductive status of overwintering D. suzukii females in Winter 2012/2013.

Dissection of females collected at Schlossleiten from August 2012 till September 2013, showed that females with maturing eggs were caught until end of November 2012 (Figs. 5 and 6). At the beginning of winter, females mostly contained immature ovarioles. Starting from February until April 2013,90\% of the trapped females mainly contained indiscernible ovarioles, suggesting oosorption $[10,11]$. First maturing eggs were found in females caught in the first week of April 2013.

One year later (winter 2013/2014) on average 50\% of the dissected females had indiscernible ovarioles (Figs. 4 and 6). An increasing percentage of mature eggs could be found from mid-March 2014, which is more than one month earlier than in 2013. In January 2014 till March 2014, about 11,000 females were caught in Schlossleiten, whereas in the same period in 2013 only 817 females were caught.

During the survey $c a$. one third of the females caught in March 2013 showed energy reserves as lipid droplets in their abdomen, while the remaining proportion obviously suffered from starvation, as they had transparent abdomens without any visible fat body, or ovarioles only fixed by filaments to the exoskeleton, or a small "imploded" abdomen. In April, females with lipid reserves in the abdomen increased rapidly to $100 \%$ of the total catch, illustrating that the females have fed.

In general, it may be assumed that, due to the mild winter 2013/2014, less individuals died and did not need lipid reserves in the fat body or to resorb eggs to cover the female's energy demands.

Comparing the sex ratio of the winters 2012/2013 and 2013/2014 at Schlossleiten it is noticeable that they have similar flight activities (Figs. 8 and 9). From September till December in both years, more males were caught than females, shifting into a higher proportion of females from January to April. This result confirms the reports by VOGT et al. (2012) [13], showing the females more temperature tolerant than males, or more females survive the winter and show up in higher numbers in spring, or there may be a seasonal sex ratio bias to the traps, which has to be proofed.

In winter 2013/2014, fly captures were almost ten times higher than the previous winter. This may be due to a lower mortality, due to the mild winter. Also, the lack of catches from mid-April is shown at Figs. 7 and 8. This could have several reasons. On the one hand, the attractiveness of the traps may have been reduced in this period, as there may be other plants which were more attractive and/or did not fit in the stimulus scheme of D. suzukii. On the other hand, the overwintering population could be decimated and the population density have been so low that in this period no $D$. suzukii were caught in the traps.

Our results showed that the microclimatic conditions of single localities are of great importance for overwintering and suggest that the flies aggregate in most favourable sites to survive hibernation at a sex ratio of 1 males per 2 females, as found at Schlossleiten. However, in such sites, a variable percentage of females show degenerated reproductive organs at the beginning of spring. Further research is needed to determine whether the degradation of reproductive organs is an irreversible phenomenon and to evaluate its impact on the population dynamics of the following season. 


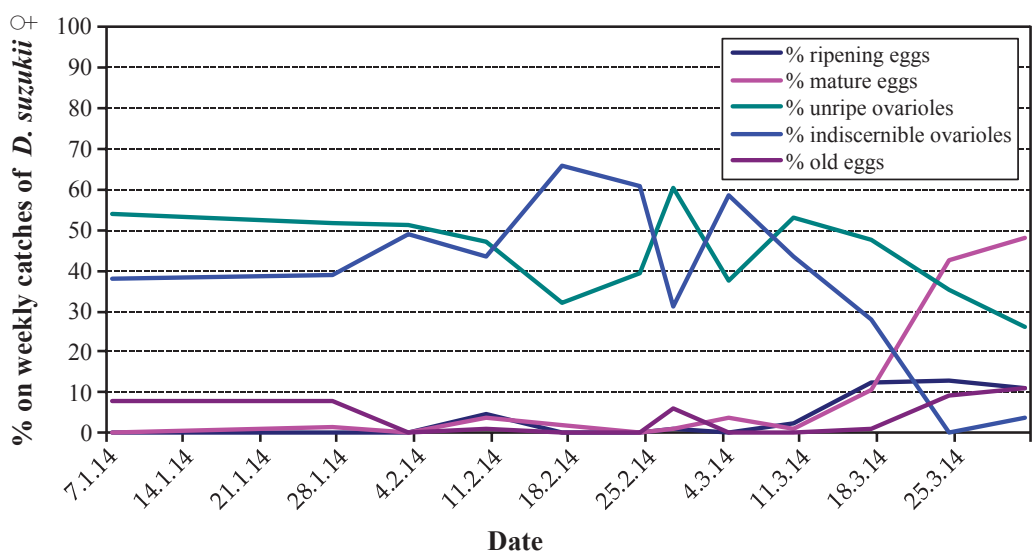

Fig. 7. Percentage distribution of reproductive status of overwintering D. suzukii females in Winter 2013/2014.

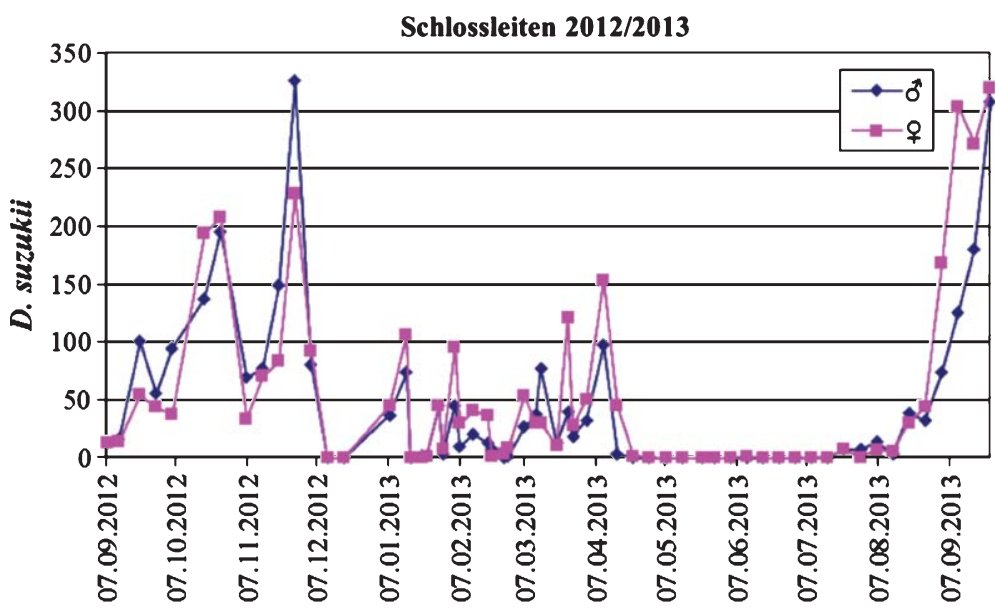

Fig. 8. Sex ratio of D. suzukii individuals trapped in the winter 2012/2013.

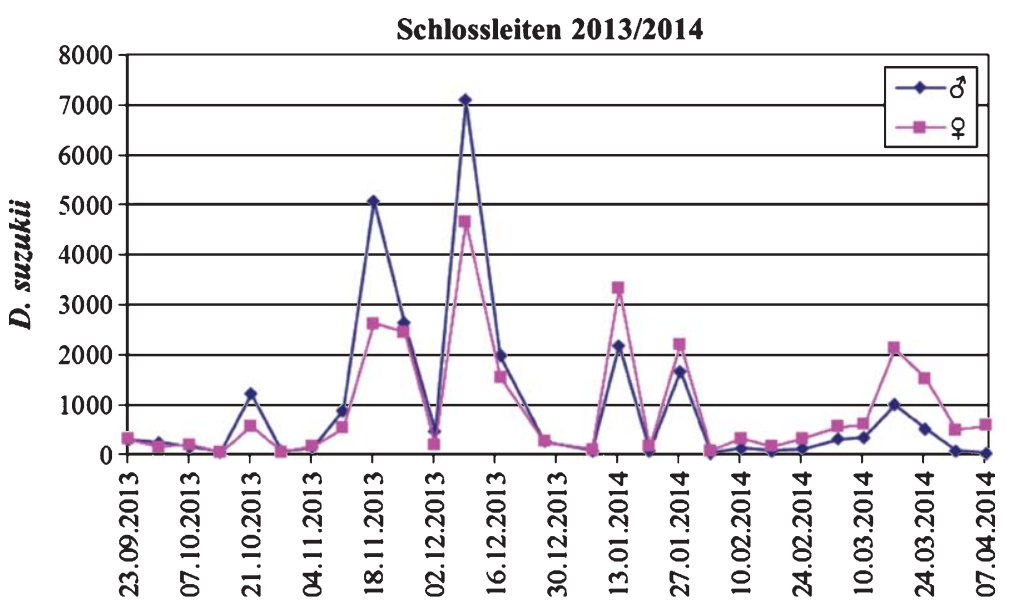

Fig. 9. Sex ratio of $D$. suzukii individuals trapped in the winter 2013/2014. 
The behaviour of the flies in mountainous sites like Barbian could not be elucidated as the air temperatures in the period January-March were mainly in a range which is assumed to suppress flight activity $\left(\leq 7^{\circ} \mathrm{C}\right)$ and flight monitoring was not possible. As the hourly temperatures in refuges did not drop below $0{ }^{\circ} \mathrm{C}$, survival of $D$. suzukii could not be excluded.

Specific data analysis of temperature and relative humidity recordings and of the flight monitoring data is ongoing as well as botanical surveys at the selected observation sites. The characterization and identification of overwintering sites may help to facilitate the development of target control strategies in order to delay the population dynamics in the following season.

\section{Acknowledgments}

We thank Dr. Heinrich Abraham for providing assistance in the botanical surveys and Dr. Martin Thalheimer for providing assistance with the climatic data loggers.

\section{References}

[1] Deprá M, Poppe JL, Schmitz HJ, De Toni DC, Valente VLS. The first records of the invasive pest Drosophila suzukii in the South American continent. J Pest Sci. 2014;87:379-83.

[2] Tochen S, Dalton DT, Wiman N, Hamm C, Shearer PW, Walton VM. Temperature-related development and population parameters for Drosophila suzukii (Diptera: Drosophilidea) on cherry and blueberry. Environ Entomol. 2014;43:501-10.

[3] Lee JC, Buck DJ, Curry H, Edwards D, Haviland DR, van Steenwyk RA, Yorgy B. The susceptibility of small fruits and cherries to the spotted-wing drosophila, Drosophila suzukii.. Pest Manag Sci. 2011;67:1358-67.

[4] Walsh DB, Bolda MP, Goodhue E, Dreves AJ, Lee J, Bruck DJ, Walton VM, O’Neal SD, Zalon FG. Drosophila suzukii: Invasive pest of ripening soft fruit expending its geography range and damage potential. J Int Pest Manag. 2011;2:1-7.

[5] Dalton DT, Walton VM, Shearer PW, Walsh DB, Caprile J, Isaacs R. Laboratory survival of Drosophila suzukii under simulated winter conditions of the Pacific Northwest and seasonal field trapping in five primary regions of small and stone fruit production in the United States. Pest Manag Sci. 2011;67:1368-74.

[6] Zerulla NF. Untersuchungen zum Verhalten und zur Ernährung der Kirschessigfliege (Drosophila suzukii, Matsumura) während der Überwinterung bis zum Beginn der Reproduktion und des Populationsaufbaues auf reifen Früchten. Master Thesis. University of Hohenheim. $2013 ; 82$.

[7] Kanzawa T. Studies on Drosophila suzukii. Mats Kofu Rev Appl Entomol. 1939;29:622.

[8] Mitsui H, Takahashi KH, Kimura MT. Spatial distributions and clutch sizes of Drosophila species ovipositing on cherry fruits of different stages. Popul Ecol. 2006;48:233-7.

[9] King RC, Rubinson AC, Smith RF. Oogenesis in Adult Drosophila melanogaster. Growth. 1956;20:121-57.

[10] Rosenheim JA, Heimpel GE, Mangel M. Egg maturation, egg resorption and the costliness of transient egg limitation in insects. Proc Biol Sci. 2000;267:1565-73.

[11] Clifton ME, Noriega FG. Nutrient limitation results in juvenile hormone-mediated resorption of previtellogenic ovarian follicles in mosquitoes. J Insect Physiol. 2011;57:1274-81.

[12] Landolt PJ, Guedot C. Field attraction of codling moths (Lepidoptera: Tortricidae) to apple and pear fruit, and quantitation of kairomones from attractive fruit. Ann Entomol Soc Am. 2008;101:675-81.

[13] Vogt H, Baufeld P, Gross J, Köppler K, Hoffmann C. Drosophila suzukii. Eine neue Bedrohung für den Europäischen Obst und Weinbau. Bericht über eine internationale Tagung in Trient am 2. Dezember 2011. Journal für Kulturpflanzen. 2012;64:68-71. 